First fossil camels from Europe

SIR - Old World fossil camels have long been known to occur in Plio-Pleistocene deposits of Asia ${ }^{1}$ and Africa ${ }^{2}$, but have only recently been recorded from Europe. The discovery of camels in Upper Miocene strata at Venta del Moro and Librilla, Spain ${ }^{3}$ (see figure), raises several questions and provides constraints to hypotheses concerning the phylogenetic roots of Old World camels.

Because of their age and geographical location, the Spanish fossils make previous hypotheses about Old World camel origins obsolete or subject to revision. The possible rates of spread of large mammals (such as camels) colonizing new continents need to be reassessed, and a general revision of Old World camelid fossils should verify previous determinations and fill gaps in the fossil record. In addition, a comprehensive comparison of Old and New World Upper Miocene and Plio-Pleistocene Camelidae may lead to a better understanding of camel phylogeny.

At first glance, the Spanish camels (zone MN 13, Uppermost Miocene, about 7.0-7.5 Myr old) appear to be the oldest known in the Old World, yet geographically they are the furthest from the continent of origin of the Camelidae (North America). This apparent anomaly is undoubtedly partly due to inconsistencies between biostratigraphical scales used in Asia, Africa and Europe. Several of the so-called Lower Pliocene sites of China
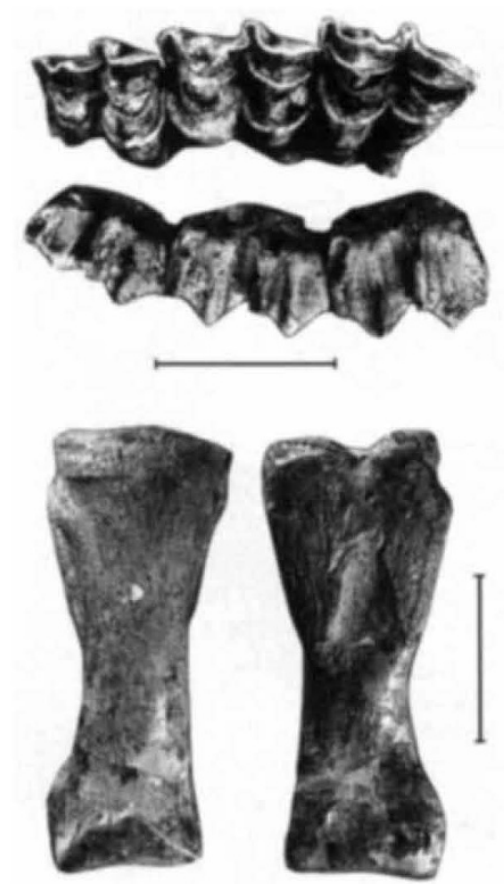

Paracamelus left maxillary molar row (occlusal and labial aspects) and first phalanx (dorsal and volar aspects) from Venta del Moro (zone MN 13), Spain. Scale bars, $5 \mathrm{~cm}$. and North Africa are in fact Uppermost Miocene, and thus are not greatly different in age from the Spanish sites. But even if the biostratigraphical scales of China and North Africa are revised to account for this, it is likely that the spread of camels to Spain, once they had crossed from the New to the Old World, was rapid, possibly a small fraction of the time represented by zone MN 13.

The absence of fossil camels in collections from other parts of Europe, despite more than a century of research, suggests that camels reached Spain from Asia via North Africa. If this is correct, then camels would have had to cross three 'choke points' in rapid succession in their spread from North America to Spain: the Bering Straits, the Red Sea and the Straits of Gibraltar.

The period of colonization of the Old World by camels was a period of generalized faunal change, with numerous lineages of mammals moving between Africa, Europe, Asia and America. It was also a period of world-wide tectogenic activity (the Rhodanian tectogenic phase $)^{4}$. The lithospheric and biospheric changes during MN 13 are thus likely to be different aspects of the same global process.

Comparison of Old World Paracamelus, to which the Spanish fossils belong, with North American Procamelus, Titanotylopus, Gigantocamelus and Megacamelus (each of which has been proposed

as the ancestral group ${ }^{5}$ may lead to the determination of the lineage from which Old World camels originated. Age constraints alone suggest that Titanotylopus and Gigantocamelus of the Blancan to Irvingtonian (4.7-0.7 Myr ago) of North America are unlikely to be ancestral to the Old World camel, unless there were two colonizations of the Old World by camels, an earlier one by Paracamelus in the Upper Miocene which became extinct, and a later one by Camelus during the Plio-Pleistocene, which still survives. It is more likely that either Procamelus (which survived in North America until the beginning of the Hemphillian (about 7 Myr ago) or Megacamelus (Late Hemphillian, 6-5 Myr ago) represents the root stock from which Old World camels originated.

Martin Pickford

Geological Survey of Namibia,

POBox 2168 ,

Windhoek 9000 , Namibia

Jorge Morales

\title{
Dolores Soria
}

Departamento de Paleobiologia,

Museo Nacional de Cencias Naturales,

José Gutiérrez Abascal 2 ,

28006 Madrid, Spain

1. Schlosser, M. Abh. Bayer. Akad. 22, 1-221 (1903).

2. Stromer, E. Z. dt. geol. Ges. 54, 108-115 (1902).

3. Morales, J., Soria, D. \& Aguirre, E. Estudios geol.36. 139-142(1980).

4. Scherba, I. G. in Global Correlation of Tectonic Movements 49-82 (Wiley, Chichester, 1987).

5. Harrison, J. A. Smithson Contr. Paleobiol. 57, 1-29 (1985)

\section{Powdered moonshine}

SIR — Daedalus (Nature 363, 404; 1993) suggested a brilliant (at first sight) idea: to increase the Moon's brightness by dispersing white magnesium oxide powder over its visible surface. This powdering would be achieved by burning magnesium in a rocket whose exhaust plume is directed at the lunar surface.

The economic and ecological advantages could be discussed. First, the averaged moonlight-to-sunlight flux ratio is equal to $A(R / 2 d)^{2}$, where $A, R$ and $d$ are the Moon albedo, radius and distance from the Earth, respectively. By increasing the albedo, this ratio can be increased from its present value of about $10^{-7}$ to at most $2 \times 10^{-6}$. This relatively small change in light flux would probably not change the Earth's climate, but the nocturnal metabolism of plants could in principle be affected. Another possible cause for concern is the contamination of near-Earth space by dust particles, as some of the powder would acquire electric charge in the exhaust plume and thus deviate from purely ballistic trajectories.

But in fact there is no need for these concerns. Daedalus's suggested method of powdering the Moon is impossible. The magnesium dust particles will be ejected at a velocity of a few $\mathrm{km}$ per second. Owing to the Moon's gravity, their impact velocity $(v)$ will always be greater than 2.5 $\mathrm{km} \mathrm{s}^{-1}$. Because this value is comparable with the velocity of sound in lunar surface material, each dust particle will form a crater. The ratio of the crater volume to the impactor volume can be expressed roughly as $\rho v^{2} / S$, where $\rho$ is the density and $S$ the maximum shear strength of the lunar surface. Because this ratio is at least $10^{3}$, nearly all the magnesium powder will be buried under lunar material.

\section{Alexeiv. Byalko}

Priroda, Moscow, Russia

DAEDALUS REPLIES - Byalko has analysed my scheme most perceptively. However, the magnesium oxide may not all be buried by cratering as he suggests. Magnesium oxide smoke can form particles less than a micrometre across; the grains of lunar regolith are also very small. They will have a shear strength and sound velocity much higher than that of bulk powder. My hope is that the impacting particles will be slowed by a series of individual collisions which may fragment them further, but will not generate a crater that buries them. 